\title{
DIVERSITY AND TAXONOMY IN CULTURAL HERITAGE
}

\author{
N.E.Myridis \\ Aristotle University of Thessaloniki, GR-54124, Thessaloniki, Greece, nmyridis@theo.auth.gr
}

KEY WORDS: Cultural Heritage Diagram (CHD), Universal Cultural Heritage Classification, Cultural Taxonomy, Cultural Heritage Preservation, Culture Categories, backbone of the Culture

\begin{abstract}
:
The discipline of Cultural Heritage is nowadays developing very well. Moreover, the field of Cultural Heritage Preservation is also developing well. The necessity of well-organized taxonomy and classification now seems to be an outstanding significant topic. The scope of this paper regards such taxonomy; more precisely, it proposes this kind of taxonomy. The final products of this paper are the Diagram of Cultural Heritage \& its Preservation and the Universal Cultural Heritage \& Preservation Classification $\left({ }_{U} C H \& P_{C}\right)$. The Cultural Taxonomy proposed here is expected to offer additive features of significant value (as for instance order, efficacy, clarification, simplicity, supervision etc.) distributed all over the individual fields of Cultural Heritage. The products of this paper are the innovative outcomes of a multifaceted research endeavor.
\end{abstract}

\section{INTRODUCTION}

We present in this article a scheme of classification for Cultural Heritage. The latter field (Cultural Heritage) is now an area with ongoing interest and research. Its inherent nature as well as the aforementioned special interest, tends to turn Cultural Heritage into a gigantic individual corpus. After that, the necessity of supervision and control in this field becomes obvious. We focus here on the hierarchical organization of the independent or cross-correlated fields of Cultural Heritage and its Preservation. Finally, we offer means for classifying the abovementioned hierarchized Cultural Heritage. A manifold and long research endeavor results in the outcomes presented here.

\section{CULTURAL HERITAGE PRESERVATION DIAGRAM [C(H\&P)D]}

It is evident that in order to sufficiently understand a field (subject, meaning etc.) an observer must initially comprehend the etymology of the name describing the field under examination. We thus give at this point a definition of the term 'Cultural Heritage'. We cite herein simply the definition with no further analysis.

Cultural Heritage is the complete space of products/objects of Culture originated from the distant Past until now.

Initially, we should observe, regarding our subject, three implicated areas. These areas are hierarchically:

\section{(a) Culture}

(b) Cultural Heritage

(c) Cultural Heritage Preservation

However, for the sake of simplicity we may abbreviate by writing as follows:

where this notation is suitable.

Cultural (Heritage (Preservation))

Hereinafter, we demonstrate a panoramic view of the whole of Culture, resulting from a thorough study. In order to successfully demonstrate this view, the most succesfull approach is by using a hierarchical diagram (the backbone of the Culture). This diagram (the Cultural (Heritage (Preservation)) Diagram $[\mathbf{C}(\mathbf{H} \& \mathbf{P}) \mathbf{D}])$ is depicted in Fig.1.
In this diagram we should notice the (sequential) succession regarding the chain Production - Heritage - Preservation; moreover, the inner classification of individual areas of Cultural Heritage Preservation. It is evident that the herein presented diagram (Fig.1) is an open diagram which can be continuously extended.

\section{CATEGORIES OF CULTURAL HERITAGE PRESER- VATION}

In the aforementioned diagram we should initially consider the following fundamental categories of culture preservation, i.e.
(1) technical
(2) digital

$\&$

The term 'technical' incorporates all those means which contribute to the physical or materialistic preservation of cultural elements (e.g. restoration (Conti \& Glanville, 2007), reconstruction etc.). The term 'digital', on the other hand, refers to each tool which helps preserve cultural elements by means of computers and digital technology (MacDonald, 2006). However, there are means which fall into one or the other category or, even, in the cross-section of them. Such a characteristic example is the use of lasers in Cultural Preservation (Fotakis et al., 2006).

Moreover, there are also other supplementary categories of preservation such as for instance audio-visual and chemical, which could be characterized as (a) subareas of the previously mentioned general categories of preservation, or (b) bilateral fields.

At last we should refer, as independent fields of Cultural Heritage Preservation, the traditional categories of Cultural Information Preservation, i.e. the imprinted and oral ones. Therefore, we may form the fundamental triptych of Cultural Heritage Preservation -with reference to its kind- as

(digital, technical, traditional) 

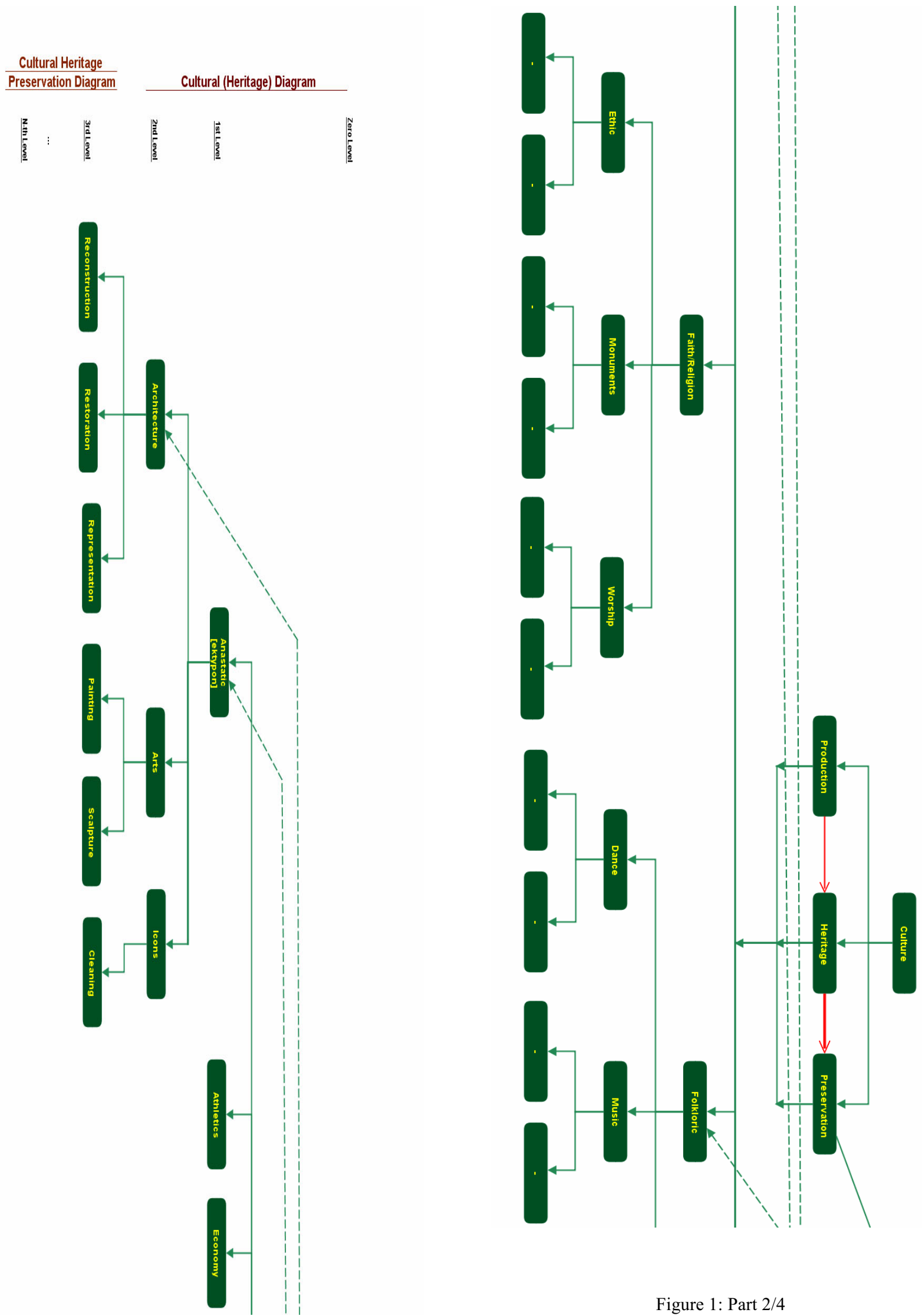

Figure 1: Part 2/4

Figure 1: Part 1/4

Figure 1: The Cultural (Heritage (Preservation)) Diagram [C(H\&P)D] 


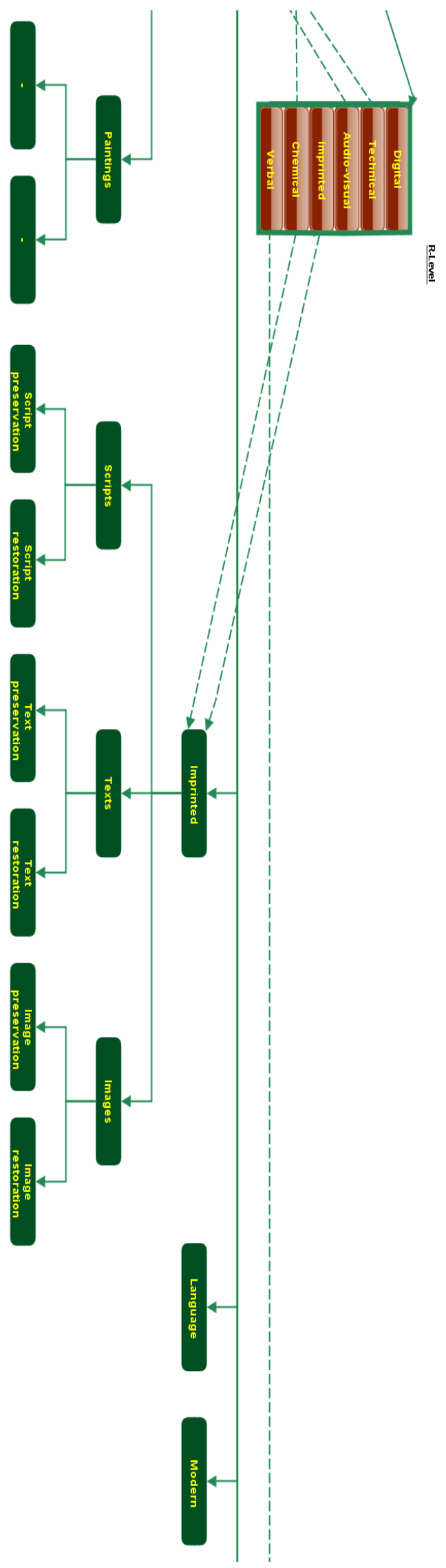

Figure 1: Part 3/4

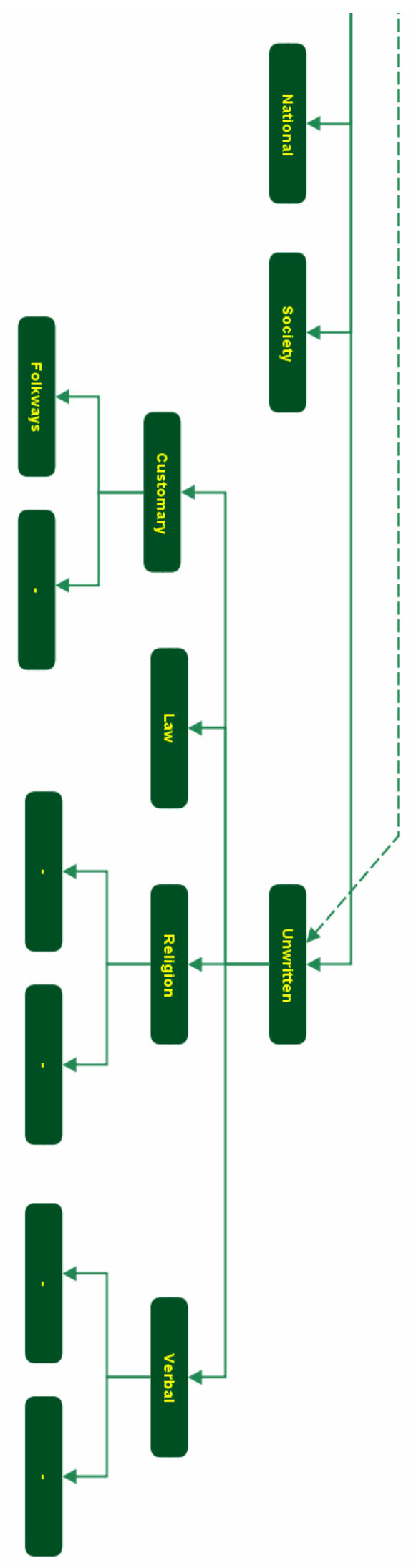

Figure 1: Part 4/4

Figure 1: The Cultural (Heritage (Preservation)) Diagram [C(H\&P)D] 
The assembly of all the previously mentioned classes of Preservation is encompassed in Table 1 .

\section{THE UNIVERSAL CLASSIFICATION SCHEME $\left({ }_{U} \mathrm{CH} \& \mathrm{P}_{\mathrm{C}}\right)$}

We now demonstrate the major product of the previous diagram $[\mathrm{C}(\mathrm{H} \& \mathrm{P}) \mathrm{D}]$, i.e. the ability to globally classify the whole area of Culture or, in other words, of the Cultural Heritage Preservation. Attempts to systematically process Culture could also be found in the literature (e.g. Hofstede et al., 2010).

According to Fig.1 we can construct a universal subject classification scheme regarding Culture and Cultural Heritage Preservation, namely the ${ }_{\mathbf{U}} \mathbf{C H} \boldsymbol{\mathbf { S }} \mathbf{P}_{\mathbf{C}}$ (Universal Cultural Heritage \& Preservation Classification). This universal classification of Culture will strongly enhance the general effort to systemise, clarify, process and promote Culture (see for instance (American Mathematical Society, 2010)). Moreover, it will contribute in conjunction with other universal efforts to efficiently resolve the megatheme of Culture (UNESCO (Frey \& Pamini, 2009) etc.)

The structure of this classification model is illustrated in Table 1 ; the zero level refers to the phase of the Culture and is codified according to the code P-H-R (stands for ProductionHeritage-Preservation). The rest of the coding scheme is also depicted in this Table. The distinctive feature of cultural preservation is - of course - its kind. The R-level (Table 1) refers to the Preservation and illustrates the different types of it. Thus, it is very important to classify cultural objects into ontological families $\left(1^{\text {st }}\right.$ level $)$, i.e. larger assemblies embodying distinct entities, using as criteria their fundamental and characteristic inherent forms (e.g. the materialistic structure of the entity, how the entity is constructed, its cross-references etc.). The $2^{\text {nd }}$ level incorporates the characteristic kinds of cultural objects. Finally, the distinctive procedures which refer to the global process of Cultural Preservation are accumulated in the $3^{\text {rd }}$ level. We should of course notice that the classification progress can proceed further in order to encompass more explicit works and processes in Cultural Heritage Preservation.

We proceed now by citing an instance of this classification scheme regarding the case of scripts' restoration; that is, the classification code $R-f f-14-F$ (according to Table 1). Furthermore, if it is necessary to specify the type of preservation (e.g. chemical) then we shall rewrite the code as $R-c-f f-14-F$.

We finally give a sample (instance) of the Universal Cultural Heritage Classification $\left({ }_{U} C H \& \mathrm{P}_{\mathrm{C}}\right)$ according to Fig.1. This instance is illustrated in Table 2. The C(H\&P) Diagram can be even more analytic, by incorporating more aspects and facets. Thus the ${ }_{\mathrm{U}} \mathrm{CH} \& \mathrm{P}_{\mathrm{C}}$ scheme could be more explicit too. Therefore we acquire through this process the ability to supervise and analytically know, in depth, the overall space of Cultural Heritage Preservation.

\section{CONCLUSION}

A specific paradox of contemporary era is obvious: the nowadays human civilization recapitulates the overall civilization of the preceding History. People during previous centuries, were creating culture all over the world; the advantage of the present era is the ability -based on its technological civilization- of storing, processing and evaluation of the overall Culture which has already been created in the past. The necessity, consequently, of a unified and systematic classification and taxonomy of the huge field of Culture becomes evident and imperative. The herein proposed Universal Cultural Heritage \& Preservation Classification $\left({ }_{\mathrm{U}} \mathrm{CH} \& \mathrm{P}_{\mathrm{C}}\right)$ scheme fulfills this need. The expected value of this classification scheme is yet inestimable.

\section{REFERENCES}

American Mathematical Society, 2010. Mathematical Subject Classification.

http://www.ams.org/mathscinet/msc/msc2010.html (accessed 17 Aug. 2012)

Conti A. and Glanville H., 2007. History of the Restoration and Conservation of Works of Art, Butterworth-Heinemann.

Fotakis C., Anglos D., Zafiropulos V., Georgiou S., and Tornari V., 2006. Lasers in the Preservation of Cultural Heritage: Principles and Applications, Taylor \& Francis, New York.

Frey B.S. and Pamini P., 2009. Making world heritage truly global: The Culture Certificate Scheme. Oxonomics, 4, pp.1-9. DOI: $10.1111 / \mathrm{j} .1752-5209.2009 .0033 . x$

Hofstede Geert, Hofstede Gert Jan and Minkov Michael. 2010. Cultures and Organizations: Software of the Mind ( $3^{\text {rd }}$ Edition), McGraw-Hill, New York.

MacDonald L. (Ed.), 2006. Digital Heritage, ButterworthHeinemann, Oxford. 


\begin{tabular}{|c|c|c|c|}
\hline \multicolumn{4}{|c|}{$\frac{\text { Zero level }}{\text { Phase }}$} \\
\hline \multirow[t]{8}{*}{$\mathbf{P}$} & \multirow[t]{8}{*}{ H } & \multicolumn{2}{|r|}{$\mathbf{R}$} \\
\hline & & \multicolumn{2}{|r|}{$\frac{\mathrm{R} \text { - level }}{\text { Type }}$} \\
\hline & & oa & audio-visual \\
\hline & & c & chemical \\
\hline & & e & digital \\
\hline & & $\mathbf{i}$ & imprinted \\
\hline & & $\mathbf{t}$ & technical \\
\hline & & $\mathbf{v}$ & verbal \\
\hline Code & \multicolumn{3}{|c|}{$\frac{\text { 1st level }}{\text { Ontology }}$} \\
\hline aa & \multicolumn{3}{|c|}{ Anastatic [ektypon] } \\
\hline bb & \multicolumn{3}{|c|}{ Athletic } \\
\hline ce & \multicolumn{3}{|c|}{ Economy } \\
\hline dd & \multicolumn{3}{|c|}{ Faith/Religion } \\
\hline ee & \multicolumn{3}{|c|}{ Folkloric } \\
\hline ff & \multicolumn{3}{|c|}{ Imprinted } \\
\hline gg & \multicolumn{3}{|c|}{ Language } \\
\hline hh & \multicolumn{3}{|c|}{ Modern } \\
\hline ii & \multicolumn{3}{|c|}{ National } \\
\hline ij & \multicolumn{3}{|c|}{ Societal } \\
\hline kk & \multicolumn{3}{|c|}{ Unwritten } \\
\hline Code & \multicolumn{3}{|c|}{$\frac{2^{\text {nd }} \text { level }}{\text { Object }}$} \\
\hline 01 & \multicolumn{3}{|c|}{ Architecture } \\
\hline 02 & \multicolumn{3}{|c|}{ Dance } \\
\hline 03 & \multicolumn{3}{|c|}{ Ethic } \\
\hline 04 & & & /Mores \\
\hline 05 & & & \\
\hline 06 & & & ges \\
\hline 07 & & & \\
\hline 08 & & & ments \\
\hline 09 & & & \\
\hline 10 & & & ings \\
\hline 11 & & & ery \\
\hline 12 & & & gion \\
\hline 13 & & & tures \\
\hline 14 & & & $p t s$ \\
\hline 15 & & & \\
\hline 16 & & & \\
\hline 17 & & & bal \\
\hline 18 & & & ship \\
\hline & & & \\
\hline Code & & & $\frac{\text { evel }}{\text { cess }}$ \\
\hline $\mathbf{A}$ & & & ing \\
\hline B & & & vation \\
\hline $\mathrm{C}$ & & & ruction \\
\hline D & & & ding \\
\hline $\mathbf{E}$ & & & atation \\
\hline $\mathbf{F}$ & & & ation \\
\hline. & & &. \\
\hline
\end{tabular}

Table 1: The hierarchical structure of the classification model ${ }_{\mathrm{U}} \mathrm{CH} \& \mathrm{P}_{\mathrm{C}}$ (Universal Cultural Heritage \& Preservation Classification) 


\begin{tabular}{|c|c|c|c|}
\hline Code & Category & Code & Category \\
\hline aa-xx & Anastatic [ektypon] & $f f-x x$ & Imprinted \\
\hline aa01 & Architecture & $\ldots$ & $\ldots$ \\
\hline $\mathrm{aa} 01 \mathrm{C}$ & Reconstruction & ff06 & Images \\
\hline aa01E & Representation & ff06B & Image preservation \\
\hline $\mathrm{aa} 01 \mathrm{~F}$ & Restoration & ff06F & Image restoration \\
\hline$\ldots$ & $\ldots$ & ff14 & Scripts \\
\hline $\mathrm{aa} 05$ & Icons & ff14B & Script preservation \\
\hline aa05A & Cleaning & ff14F & Script restoration \\
\hline$\ldots$ & $\ldots$ & ff 15 & Texts \\
\hline aa10 & Paintins & ff15B & Text preservation \\
\hline$\ldots$ & $\ldots$ & $\mathrm{ff} 15 \mathrm{~F}$ & Text restoration \\
\hline aa13 & Scalptures & $\ldots$ & $\ldots$ \\
\hline aa13A & Cleaning & gg-xx & Language \\
\hline .. & $\ldots$ & hh-xx & Modern \\
\hline bb-xx & Athletic & $\ldots$ & $\ldots$ \\
\hline cc-xx & Economy & ii-xx & National \\
\hline dd-xx & Faith/Religion & $\ldots$ & $\ldots$ \\
\hline$d d 03$ & Ethic & jj-xx & Societal \\
\hline$d d 08$ & Monuments & $\ldots$ & $\ldots$ \\
\hline$d d 18$ & Worship & kk-xx & Unwritten \\
\hline.. & $\ldots$ & $k k 04$ & Folkways/Mores \\
\hline ee-xx & Folkloric & kk04D & Recording \\
\hline$e e 02$ & Dance & $k k 07$ & Law \\
\hline$e e 09$ & Music & $k k 12$ & Religion \\
\hline ee10 & Paintings & $k k 17$ & Verbal \\
\hline$\ldots$ & $\ldots$ & .. & $\ldots$ \\
\hline
\end{tabular}

Table 2: An instance of the Universal Cultural Heritage \& Preservation Classification $\left({ }_{\mathrm{U}} \mathrm{CH} \& \mathrm{P}_{\mathrm{C}}\right)$ 